\title{
Preliminary Analysis on Organizational Factors Influencing Effective Construction Risk Management: A case study of Nigerian Construction Companies
}

\author{
A.Q. Adelekea, ${ }^{*}$, A.Y. Bahaudina, A.M. Kamaruddeen ${ }^{b}$ \\ aSchool of Technology Management, Universiti Utara Malaysia, 06010 UUM Sintok, Kedah, Malaysia \\ ${ }^{b}$ Department of Quantity Surveying, School of Built Environment, University College of Technology, Sarawak, Sibu, Malaysia \\ *Corresponding author: aadekunle0@gmail.com
}

\begin{abstract}
An increased demand has been placed on construction projects for more accountability to their clients with measure to the company products and services. However, this demand is because of innumerable antecedent factors repelling effective risk management in construction projects. Therefore, finishing the projects is not only the concern of the industries but also managing the risks involved with the projects. The impacts of effective risk management on the performance of these industries are as well important. The objective of this study is twofold: (i) to propose an inclusive framework which comprises of the antecedent factors proposed in the framework to improve effective risk management in Nigeria construction companies (ii) to measure the instrument used for the preliminary analysis in this study. Data were collected from forty respondents using seventy-five items instrument. SPSS software was used to analyze the data collected for the pilot test. The results of the Cronbach's Alpha test disclosed a strong internal reliability of the overall instrument and the construct. This research is significant because it explores the implementation of some organizational factors which will influence construction risks and will also improve effective risk management in Nigeria construction projects, and the validation of the instrument which requires further exploration of the constructs in future study.
\end{abstract}

Keywords: Effective construction risk management, framework, instrument, validation and reliability

(C) 2016 Penerbit UTM Press. All rights reserved

\subsection{INTRODUCTION}

Risk management is the term designated to the formalized process of harmonizing the risks and opportunities which a decision may results to and this includes proper action to produce an adequate balance in between the two. The way this process is frequently performed, is by using an experience and intuition, which is specific to the individual [1].

Furthermore, risk management is commonly recognized as one of the greatest important capability and procedures areas under the umbrella of project management [7]. As the fact still remain that each construction project is dynamic and unique, construction operation comprises of several uncertainties, varies techniques, multiple intricacies, and divergent environments. Thus, identifying and managing the possible risk factors, which can importantly differ from one project to another contingent on various conditions, which plays a vital role in improving the performance and achieving the successful delivery of the project [33].

[23] defined risk as a "form of situations involving many unexpected, unknown, often unpredictable and frequently undesirable factors." [52] perceived risk as "a condition or an uncertain event that, if it arises, has a negative or positive effect on a project objective" Jaafari [31]. In addition, stated risk as "the exposure to loss, gain, or the probability of occurrence of loss/gain multiplied by its respective magnitude", while [2] described risk by "the possibility of injury, loss, destruction or disadvantage".

Despite the massive breath of literatures on risk, following [10], the researcher further propose the following definition of risk as "the probability of occurrence of any unexpected or ignored event that can hinder the achievement of project objectives or performance."

More so, it has been affirmed by various literatures such as [19]; [36]; [45]; [14]; [1]; [60]; [24]; [35]; [30]; [59]; [32], that certain internal organizational factors (effective communication, team competency and skills and active leadership) and external organizational factors (political, organizational cultural, technology and economic factors) have a relationship with effective construction risks management with moderating effects of rules and regulations as it was used by $[29,20,46,28,5]$.

Yet, the influence of Organizational factors on effective construction risk management among the construction companies operating in Abuja and Lagos State Nigeria have not received considerable attention. Abuja and Lagos state were used in this study because they are the hearth of Nigerian construction market, and were most of the construction companies have their headquarters.

Therefore, to elucidate the inconclusive assertions on the relationship between the internal and external organizational factors to the effective construction risks management, a comprehensive framework is needed which will integrate these factors via the moderating roles of rules and regulations in the Nigeria construction industries. 


\subsection{CONCEPTUAL FRAMEWWORK}

Previous literature reviewed on the concept of effective risk management in construction projects, has shown a coherent need for a framework that will incorporates the antecedent factors (internal and external organizational factors and construction risks), through the moderating role of rules and regulations from the Nigerian government perspectives in a single study.

However, in this study effective construction risks management is the dependent (criterion) variable while the independent (predictor) variables are the antecedents of internal organizational factors which are also known as intangible organizational resources in this study such as; (effective communication, team competency and skill, active leadership) conceptualized following [19,36]. While external organizational factors which are regarded as factors that are beyond the organizational control such as; (political, organizational culture, technology, economic factors), following [14, 1, 48]. Rules and regulations as the moderator on the relationship between internal and external organizational factors and effective construction risks management, following [29, 20, 46]. In the light of that, it is a general belief and regarded in risk management literatures that certain factors influenced effective risks management during the construction process. The proposed framework for this study is depicted in Figure 1.

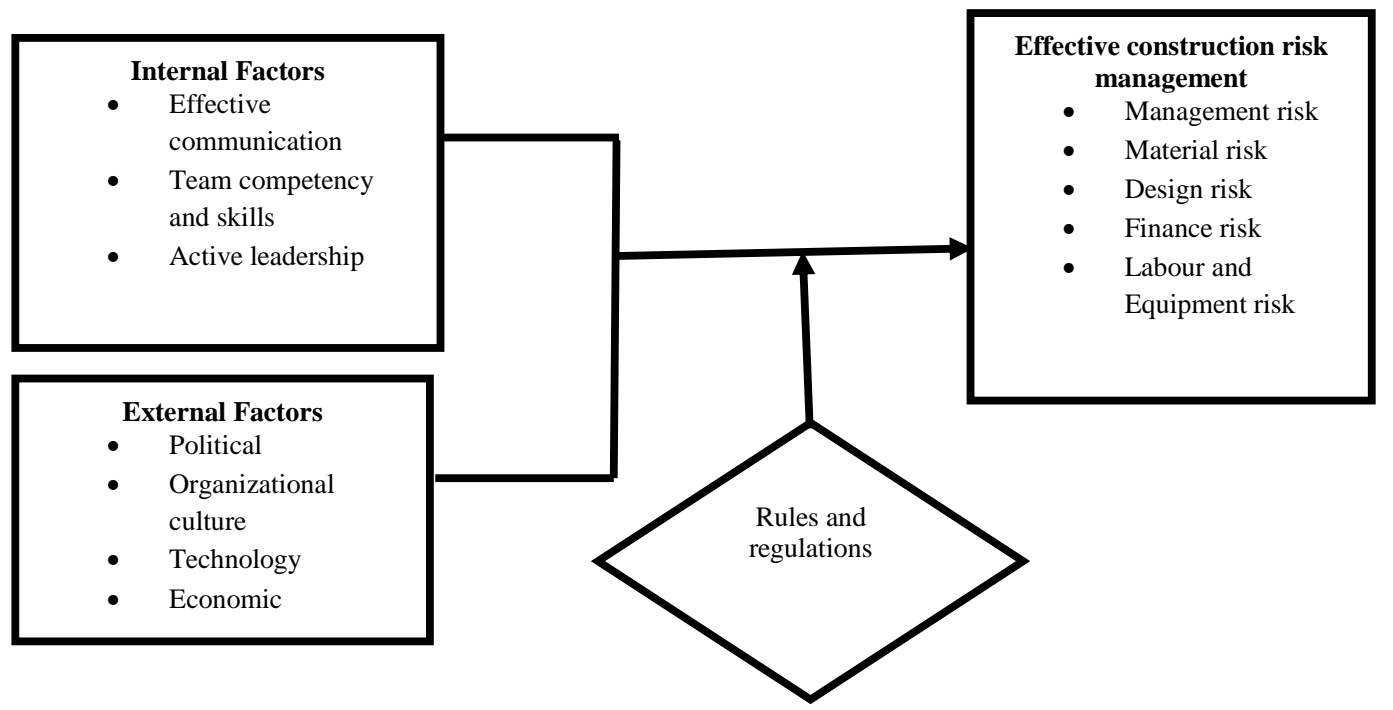

Figure 1 Conceptual framework

\section{Effective Communication}

In most cases, effective communication can be seen as hidden element for success. The disposition of the research warrant this variable and to see its relationship with dependent variable as stated in the research theoretical framework. Open, reliable and frequent communication is pivotal for successful project with less risk.

However, effective communication is vital for any organization and project team. It is required that authentic and clear information is shared at right time, right place and to right person during the construction project. Flow of information, top down/downward and bottom up/upward communication is an important aspect of project to think about. It reduces conflicts, improve decision making and effect on team member performance to their project manager, so lack of all these attributes will influence or affect effective construction risk management in the organization [14]. The empirical investigation of [19]; [36]; [45]; [1], also confirms that effective communication positively influenced effective construction risk management.

\section{Team Competency and Skill}

Team competency and skills is an important variable to be considered, because it provides knowledgeable and technical human resource which is required for contractors, project managers and team members to achieve the project goals

According to [21], team competency and skills can be seen in terms of skills, knowledge and attitude. Team dynamics are also connected with team competency; that is what type of characteristic team have and what are the characteristics required for the project execution, thus, any organization that lacks team competency and skills, will definitely affect effective construction risk management. [45] and [19] highlighted a positive relationship between team competency and skills with effective construction risk management.

\section{Active Leadership}

Most of the previous studies focus on leadership styles, behavior and strategies. Successful project required different kind of leadership from the normal routine project work. In construction project, there are needs for active leaders which can take serious actions on run time in order to avoid making situation worse. Active leader is one of the most important independent variable proposed in the theoretical framework. Project leader's priority is to run project in emergency situation as it will be run in normal condition Barber \& Wan [9]. Thus, any organization without active leadership will certainly affect effective construction risk management. The empirical investigation of [60] and [21] concluded that active leadership positively influenced effective construction risk management. 


\section{Political Factor}

According to [31], the influence of environmental variables such as safety, community perception, and legal acceptability, political and social impacts on project is mostly high. It was further explain by the author that political factors includes, discriminatory legislative, covering tax regimes, riots, strikes, civil unrest, wars, terrorism, invasions and religious turmoil will positively influence effective construction risk management in an organization. The study of [1] affirmed a positive influenced of political factors on effective construction risk management.

\section{Organizational Culture}

[25] and [58] perceived organizational culture as the elementary assumptions, values, beliefs and models of behavior, practices, rituals, heroes, symbols, technology and artefacts. In addition, [26] indicated that organizational culture is a strong tool that is associated with "behavior and attitude" of contractors, project managers and team members during execution of project which significantly influenced effective construction risk management positively.

\section{Technological Factor}

According to [3] technology is the views of an environment which must be considered in developing countries strategic plans. [49] asserted that a suitable and proper construction technology can be measured by the presence of plant and equipment that are made locally, magnitude of local material resources and the level of utilization of the local construction resources, and the skilled manpower resources. The studies of [64], [61] revealed that technology as an external factor significantly influenced effective construction risk management positively.

\section{Economic Factor}

The economic and financial aspect of an organization depend on the level of universal economic activity, as well as the available resources to execute the work, which includes the economic competition of several level around the appointment of all parties involved in building projects [47]. The empirical investigation of [48] and [1] also confirms that economic as an external factor positively influenced effective construction risk management.

\section{Effective Construction Risk Management}

The construction industry, compare to other industry, is risky. However, construction project are comprehended to have more underlying risks due to many contracting parties involved such as contractors, subcontractors, clients, designers and engineers. There is uniqueness in construction projects because they are built only once. The parties also include irregular project team which are accumulated from different companies, countries and cultures. Moreover, the complexity and size of construction projects are growing higher which add to the risks. This is because of the social, cultural, political and economic situations where the project is to be contracted [15].

Risk in construction has been the mark of attention by most of the construction parties because of cost and time overruns that are connected with construction project.

The word "risk" has been defined in several ways. While [53]; [27]; [52] have perceived risk as an experience to economic loss or gain growing from participation in the construction process; [44] and [41] have viewed this as an experience to only loss. [11] and [10] defined risk that are related to construction as a condition through which the process of construction project leads to uncertainty in the last cost, time and quality of the project. In this study, construction risk is defined as the probability of occurrence of some uncertainty, that hinder the achievement of project objectives, which it can be from management, materials, design, finance and labour and equipment risks.

According to [54], twenty-eight major construction risks factors which leads to delay due to improper effective construction risk management with their effects on the construction projects in Malaysia were identified such as inadequate finance and payments for completed project; lack of materials; labour supply; failure and equipment availability; poor communication between parties; and misapprehension during the construction stage were the leading factors.

Consistent with study of [3] that identified forty-four risk factors that leads to delay due to deficiency of effective construction risk management among construction projects in Nigeria, the study revealed major risk factors such as; management, material, finance and design risk factors. [17] and [63] affirmed a positive relationship between internal and external organizational factors and effective construction risk management, Consistent with the study of [2] in USA which revealed a positive relationship between internal, external organizational factors and effective construction risk management.

\section{Moderating Effects of Rules and Regulations}

Rules and regulations are enacted to control the risks occurrence on construction project caused by management, material, design, finance and labour and equipment. Therefore, construction industry are mandated to operate under the requirements of rules and regulations [16, 29, 28]. Previous researcher's results have shown that rules and regulations that are focused on the construction industry have a set of positive significance on construction projects and performance of the construction industry Ismail; Aniekwu; Niu [29, 6, 46]. In the presence of an immense attention of clients, stakeholder's pressure and the top management allegiance, a suitable rules and regulations is the best approach to reduce risks occurrence on construction projects. Rules and regulations strengthens the implementation of internal and external organizational factors by providing standard requirements for organizational conformances. Thus, there is need for rules and regulations compliances to strengthen the dedication of construction industry to minimize risks occurrence on projects.

In the same vein, [29] revealed that in Malaysia context, rules and regulations on housing stated that, there must be a replacement for the traditional building practices by an industrialized building system (IBS), which on the long run might save labour, cost, confer quality 
and durability and time of construction in Malaysian construction companies as cited by [5]. Similarly, the study of [28] revealed that government rules and regulations influenced construction projects in Nigeria, such as the importations of the construction materials and taxes. Below are the hypothesis between the moderating variable and the two constructs of the predictor with the criterion variable.

\subsection{METHODOLOGY AND ANALYSIS}

This study is a cross-sectional research design. Which means, data were collected at a single-point-in-time using structured questionnaire Kumar, Abdul Talib \& Ramayah; [39,57]. However, proportionate stratified random sampling techniques was also employed in the ongoing research. The research approach is quantitative, which is a research approach that is mostly adopted in social sciences [55]. Considering this study as the pilot test of an on-going research which was conducted in Abuja and Lagos Nigeria on 19th, June 2015, among the contract manager, executive director, marketing manager, project manager and engineer, According to [40], a pilot study mostly necessitates a range of (15-50) respondents. Therefore, a total number of fifty (50) questionnaires were personally distributed with the return rate of forty (40) which is suitable for the pilot study analysis.

\section{Instrument Design}

[8] affirmed questionnaire as one of the appropriate survey instrument for research. To make sure all the variables in this research framework are all measured, items for this study were adapted from various sources in order to create item pool and content validity which include previous research findings on the construct of this study (internal and external organizational factors, effective construction risks management, government rules and regulations. These items were adapted and modified from preceding literatures $[38 ; 31 ; 34 ; 62 ; 3 ; 42]$ with the purpose of creating the validity of the construct including (a) create contact prior to the main study between the researcher and the organizations (b) ascertain the reliability of the constructs and (c) anticipate the likely challenges that may arise before the actual data collection of the study. Similarly, the study adopted the use of five-point likert scale rating from $0.1=$ 'very low,' $0.3=$ 'low', $0.5=$ 'medium', $0.7=$ 'high', $0.9=$ 'very high', to measure the feedback to the questionnaires.

A rating scale helps the researcher in computing the standard deviation and the mean feedback on variables and also the mid-point of the scale [56]. Previous literatures like [37] argued that any scale between 5-7 points, have a propensity of a high reliably and validly measure items compare to a shorter or a longer rating. However, [13] and [18] proposed that the choice of the measurement scale mostly depends on the taste of the researcher since there is no single superlative method of constructing a scale. An appropriate method for one research problem might appropriate for another. It was further argued by [37] that the conduct established by respondents is either to satisfy or optimize the survey. Thus, this study adopts the use of a five-point likert scale in order to avoid the respondents from selecting an unbiased point which may reduce the quality of the questionnaire.

More so, all the constructs/variables in this study are multidimensional. The detail of the constructs and their analogous dimensions are depicted in Table 3.1.

\section{Validation of Instrument}

The pilot study of this research was conducted in Abuja and Lagos Nigeria. Respondents in this study are contract manager, executive director, marketing manager, project manager and engineer. The purpose of this was to get an appropriate feedback

to improve the instrument and data collection techniques used in the main survey. In checking that the questionnaire was accurately adapted, this research conducted a construct and content validity. The important of the this validity is to ascertain whether a meaningful illations can be highlighted from the instrument of this study by conducting a face validity test on the sequence and wordings of all the items to determine which one is appropriate for the respondents among all the alternative styles, to be sure whether the items of this survey will effectively measure the concepts hypothesized for this study and to come out with a back-up plan to tackle any challenges which may arise at the point of actual data collection process [12].

This was done by firstly exposing the instrument of this survey to an in-depth assessment by the practitioners and experts in quantitative, [12] and next was making appropriate corrections based on the feedback comments received from the experts.

The validation process comprises of six (6) experts, of which four (4) among the experts were academicians while two (2) are practitioners. The feedback comments received from them was implemented in the final survey instrument used in data collection for the main study.

\section{Relaibility Test for the Construct}

After the assessment of the research instrument from the experts view, further test known as the reliability test was also conducted to know the internal consistency of the research instrument. [50] affirmed that forty (50) or more respondents are sufficient enough to conduct a pilot testing. However, fifty (50) questionnaires was sent out and forty (40) was returned from the respondents which is reliable for the purpose of the pilot study in this research. The pilot survey results for this research was interpreted with the following analysis such as; descriptive statistic and Cronbach's Alpha value depicted in Tables 1. 
Table 1 Source of measurement

\begin{tabular}{|c|c|c|c|c|}
\hline $\mathbf{S} / \mathbf{N}$ & Constructs & Dimensions & Source & Remarks \\
\hline 1 & Internal factors & $\begin{array}{l}\text { Effective communication } \\
\text { Team competency and skills } \\
\text { Active leadership }\end{array}$ & Kumaraswamy \& Chan (1998) & Adapted \\
\hline 2 & External factors & $\begin{array}{l}\text { Political factor } \\
\text { Organizational culture } \\
\text { Technology factor } \\
\text { Economic factor }\end{array}$ & $\begin{array}{l}\text { Jaafari (2001) } \\
\text { Kamaruddeen } \text { et al., (2012) } \\
\text { Sun \& Meng (2009) } \\
\text { Sun \& Meng (2009) }\end{array}$ & Adapted \\
\hline 3 & Government policy & Rules and regulations & Mezher \& Tawil (1998) & Adapted \\
\hline 4 & $\begin{array}{l}\text { Effective construction risks } \\
\text { management }\end{array}$ & $\begin{array}{l}\text { Management } \\
\text { Material } \\
\text { Design } \\
\text { Finance } \\
\text { Labour and equipment }\end{array}$ & Aibinu \& Odeyinka (2006) & Adapted \\
\hline
\end{tabular}

Table 2 Descriptive profile of the respondents

\begin{tabular}{lll}
\hline Respondents & Frequency & Percentage (\%) \\
\hline Position in the company & 3 & \\
Contact manager & 0 & 0.5 \\
Executive director & 1 & 2.5 \\
Marketing manager & 5 & 12.5 \\
Project manager & 12 & 30.0 \\
Engineer & 19 & 47.5 \\
Other staff like safety man and surveyors & & \\
\hline Working experience (Years) & 1 & 2.5 \\
Lowest working experience & 9 & 22.5 \\
Highest working experience & & \\
\hline Gender & 32 & 80.0 \\
Male & 8 & 20.0 \\
Female & & \\
\hline
\end{tabular}

Table 3 Descriptive profile of the companies

\begin{tabular}{lll}
\hline Parameters & Frequency & Percentage (\%) \\
\hline Company specialization & & \\
Apartment buildings & 4 & 10.0 \\
Roads & 34 & 85.0 \\
Bridges & 2 & 5.0 \\
Other & 0 & 0 \\
\hline Company ownership type & & \\
Local & 5 & 12.5 \\
National & 7 & 17.5 \\
Multi-national & 28 & 70.0 \\
Others & 0 & 0 \\
& & \\
\hline
\end{tabular}

\subsection{RESULTS AND DISCUSSION}

This study has highlighted the possible reason behind high risk occurrence on Nigerian construction projects and improper effective risk management in the industries, this could be because previous researcher failed to consider certain internal and external organization factors and failed to implement rules and regulations as moderator on these relationships. This research therefore presented a framework that integrates the internal and external organizational factors, effective construction risks management with the use of rules and regulations in a single framework. This research is one among others that considers the effect of rules and regulations on the relationship between internal and external organizational factors and effective construction risks management. This proposed framework is developed through a thorough matrix and review of literatures to provide a deep understanding to academicians and practitioners on the internal and external organizational factors with effective construction risks management and moderated by rules and regulations to enable policy maker enhance construction projects and manage risk effectively through rules and regulations.

The results for the pilot test analysis indicated that the Cronbach's Alpha of the variable ranges from lowest to highest [51] and [22] affirmed that Cronbach's Alpha greater than 0.7 is accepted; however, value greater than lowest is preferable. This result depicts that the values of the Cronbach's Alpha are all greater than lowest indicating a very good reliability of the research instrument with (0.868) for effective communication as the highest and (0.840) as the lowest for management risks. Therefore, none of the items were dropped from 
the instrument. The reliability result of this study revealed that the variables as depicted in Table 1 are appropriate to be used in the main data collection for the purpose of the analysis of the actual or future research.

Furthermore, reliability analysis is expected to be performed on the actual data collected after conducting factor analysis on the main or future study based on a larger sample size.

\subsection{CONCLUSION}

This study is limited to the organizational stewardship aspect of risk management practices in the construction industry. Therefore, future researchers are charged to investigate the social and economic aspects of risk management practices. However, since this study is to test if the research instrument used during the pilot study will measure what we intent to measure, therefore, future study are to empirically validate the proposed framework in this study.

\section{References}

Abu Hassan, B. A. B., Ali, K., Onyeizu, E. N., \& Yusof, M. N. (2012). Evaluating Risk Management Practices in Construction Company: Evidence from Oman. International Journal of Academic Research, 4(2), 32-37.

Ahmed, S. M., Azhar, S., Castillo, M., \& Kappagantula, P. (2002). Construction Delays in Florida: An Empirical Study. Final Report. Department of Community Affairs, Florida, US.

Aibinu, A. A., \& Odeyinka, H. A. (2006). Construction Delays And Their Causative Factors In Nigeria. Journal Of Construction Engineering And Management, 132(7), 667-677.

Akanni, P., Oke, A., \& Akpomiemie, O. (2014). Impact Of Environmental Factors On Building Project Performance In Delta State, Nigeria. HBRC Journal.

Alaghbari, W. E., Kadir, M. R. A., \& Salim, A. (2007). The Significant Factors Causing Delay Of Building Construction Projects In Malaysia. Engineering Construction and Architectural Management, 14(2), 192-206.

Aniekwu, A. (1995). The Business Environment Of the Construction Company in Nigeria. Construction Management and Economics, 13(6), 445-455.

Artto, K. A. (1999). Management across the Organization. Quest FOR Team Competence Software Project Management Organizational Change AS A Project Factors Impeding Project Management Learning, 5(1), 4.

Asika, N., 1991. Research Methodology In The Behavioral Science. Lagos: Longman Nigeria Plc, Nigeria.

Barber, E., \& Wan, J. (2005). Leadership In Project Management: From Firefighter To Firelighter, Management Decision, 43 (7/8), $1032-1039$.

Bothroyed, C. \& Emmett, J., (1998). Risk Management - A Practical Guide For Professionals. London, UK: Whitherby \& Co Ltd.

Bufaied, A. (1987). Risks In The Construction Company: Their Causes And Their Effects At The Project Level. University of Manchester, Institute of Science and Technology.

Creswell, J.W., (2009). Research Design: Qualitative, Quantitative And Mixed Methods Approaches. $3^{\text {rd }}$ Edn., Los Angeles: Sage Publications Ltd.

Dawis, R.V., (1987). Scale Construction. Journal of Counseling Psychology, 34(4): 481-489.

Doloi, H. (2009). Relational Partnerships: The Importance Of Communication, Trust And Confidence And Joint Risk Management In Achieving Project Success. Construction Management and Economics, 27(11), 1099-1109.

El-Sayegh, S. M. (2008). Risk Assessment And Allocation In The UAE Construction Company. International Journal of Project Management, 26(4), 431-438.

Flanagan, R., \& Norman, G. (1993). Risk Management And Construction. Oxford, Blackwell Science Ltd.

Frimpong, Y., Oluwoye, J., \& Crawford, L. (2003). Causes Of Delay And Cost Overruns In Construction Of Groundwater Projects In A Developing Countries; Ghana As A Case Study. International Journal of Project Management, 21(5), 321-326

Garland, R., 1991. The midpoint on a rating scale: Is it desirable? Marketing Bulletin, 2(May): 66-70.

Geraldi, J. G., Lee-Kelley, L., \& Kutsch, E. (2010). The Titanic Sunk, So What? Project Manager Response To Unexpected Events. International Journal of Project Management, 28(6), 547-558.

Gibb, K. (2011). Delivering New Affordable Housing In The Age Of Austerity: Housing Policy In Scotland. International Journal of Housing Markets and Analysis, $4(4), 357-368$

Greenberg, J., \& Baron, R.A. (2008). Behavior In Organizations, 9th edition, New Jersey: Pearson prentice hall.

Hair, J., W.C. Black, B.J. Babin and R.E. Anderson, (2010). Multivariate Data Analysis. 7th Edn., Uppersaddle River, New Jersey: Pearson Education International.

Hartog, D. N., \& Verburg, R. M. (2004). High Performance Work Systems, organisational culture and firm effectiveness. Human Resource Management Journal, $14(1), 55-78$.

Healy, J. R. (1982). Contingency Funds Evaluation. Association for the Advancement of Cost Engineering (AACE) Transactions.

Hertz, D. B., \& Thomas, H. (1983). Risk Analysis And Its Applications: Wiley Chichester etc.

Ho, S. S., \& Pike, R. H. (1992). The Use Of Risk Analysis Techniques In Capital Investment Appraisal. Risk Analysis Assessment and Management, 71-94.

Hofstede, G., Neuijen, B., Ohayv, D. D., \& Sanders, G. (1990). Measuring Organizational Cultures: A Qualitative And Quantitative Study Across Twenty Cases. Administrative Science Quarterly, 286-316.

Iroegbu, A.N. (2005). Housing In Nigeria: A Role Of The Construction Company. In A.I. Kalu \& G.N. Chima (eds). Housing development in Nigeria: Concepts, Issues And Strategies. Abakaliki: Pauliton press.

Ismail, E. (2001). "Industrialized Building System For Housing In Malaysia”, Paper Presented at the 6th Asia Pacific Science and Technology Management Seminar, Tokyo.

Israelsson, N., \& Hansson, B. (2009). Factors Influencing Flexibility In Buildings. Structural Survey, 27(2), 138-147.

Jaafari, A. (2001). Management of risks, uncertainties and opportunities on projects: time for a fundamental shift. International Journal of Project Management, 19(2), $89-101$.

Jabnoun, N., \& Sedrani, K. (2005). TQM, Culture, And Performance In UAE Manufacturing Firms. Quality Management Journal, $12(4), 8$.

Jarkas, A. M., Haupt, T. C., \& Haupt, T. (2015). Major Construction Risk Factors Considered By General Contractors in Qatar. Journal of Engineering, Design and Technology, 13(1).

Kamaruddeen, A. M., Yusof, N. A., Said, I., \& Pakir, A. H. K. (2012). Organizational Factors and Innovativeness of Housing Developers. American Journal of Applied Sciences, 9(12).

Kangari, R., \& Riggs, L. S. (1989). Construction Risk Assessment By Linguistics. Engineering Management, IEEE Transactions on, 36(2), $126-131$.

Karim Jallow, A., Demian, P., N. Baldwin, A., \& Anumba, C. (2014). An empirical study of the complexity of requirements management in construction projects. Engineering, Construction and Architectural Management, 21(5), 505-531.

Krosnick, J.A. and L.R. Fabrigar, 1991. Designing Rating Scales For Effective Measurement In Surveys. In B. Lyberg, P. Colllins, M. De Leeuw, E. Dippo, C. Schwarz, N. (Ed.), Survey Measurement And Process Quality. (Trewined.). New York: John Wiley \& Sons, Inc.

Kumar, M., Abdul Talib, S., \& Ramayah, T. (2013). Business Research Methods. New York: Oxford University press.

Kumaraswamy, M. M., \& Chan, D. W. (1998). Contributors To Construction Delays. Construction Management \& Economics, 16(1), 17-29.

Malhotra, N.K., 2008. Essentials Of Marketing: An Applied Orientation. 2nd Edn., Australian: Pearson Education.

Mason, G. E. (1973). Quantitative Risk Management Approach to the Selection of Construction Contract Provisions: Department of Civil Engineering, Stanford 
University.

Mezher, T. M., \& Tawil, W. (1998). Causes Of Delays In The Construction Company in Lebanon. Engineering, Construction and Architectural Management, 5(3), $252-260$.

Mills, A. (2001). A systematic Approach To Risk Management For Construction: Structural Survey. Victoria, Australia, University Press: University of Melbourne. Moavernzadeh.F.\& Rasow.J.(1999). Risks and risk analysis in construction management, Proceedings of the CIB W65, Symposium on Organization and Management of Construction, US National Academy of Science, May, 1999, Washington DC, USA.

Moe, T. L., \& Pathranarakul, P. (2006). An Integrated Approach To Natural Disaster Management: Public Project Management And Its Critical Success Factors. Disaster Prevention and Management, 15(3), 396-413.

Niu, Y. (2008). The Performance And Problems Of Affordable Housing Policy In China: The Estimations Of Benefits, Costs And Affordability. International Journal of Housing Markets and Analysis, 1(2), 125-146.

Obalola, T.F, (2006). Evaluation Of The Effects Of Project Environment On Project Performance in Lagos and Abuja, Nigeria (dissertation), Federal University Technology, Akure, Nigeria.

Odeh, A. M. \& Battaineh, H. T. (2002). Causes Of Construction Delay: Traditional Contracts. International Journal of Project Management, 20(1), 67-73.

Oladapo, R.A, Olotuah, A.O, (2007). Appropriate Real Estate Laws And Policies For Sustainable Development In Nigeria, J. Struct. Surv. 25 (3/4), $330-338$.

Pallant, J., 2001. SPSS Survival Manual: A Step By Step Guide To Data Analysis Using SPSS For Windows. 3rd Edn., England: Mcgraw Hill Open University Press.

Pallant, J., 2011. SPSS Survival Manual: A Step By Step Guide To Data Analysis Using SPSS program. England: McGraw Hill Open University Press.

Perry, J.H. and Hayes, R.W. (1985), "Risk and Its Management In Construction Projects", Proceedings of the Institution of Civil Engineering, 78(3), 499-521.

Porter, C. (1981). Risk Allowance In Construction Contracts. Unpublished MSc. project report.

Sambasivan, M., \& Soon, Y. W. (2007). Causes And Effects Of Delays In Malaysian Construction Company. International Journal of Project Management, 25(5), $517-526$.

Schein, E. H. (2004). Organizational Culture and Leadership.

Scupola, A. (2003). The Adoption Of Internet Commerce By Smes In The South Of Italy: An Environmental, Technological And Organizational Perspective. Journal of Global Information Technology Management, 6(1), 52-71.

Sekaran, U. and R. Bougie, 2009. Research Methods For Business: A Skill Building Approach. 5th Edn., United Kingdom: John Wiley \& Sons Ltd.

Sekaran, U., 2003. Research Methods For Business. 4th Edn., New York: John Wiley \& Sons Inc.

Sekaran, U., Robert, Y. C., \& Brain, L. D. (2001). Applied Business Research.1st Edition. Australia: John Wiley \& Sons Australian Ltd.

Simpkins, R. A. (2009). How Great Leaders Avoid Disaster: The Value Of Contingency Planning. Business Strategy Series, 10(2), 104-108.

Sommerville, J., \& Craig, N. (2006). Implementing IT in construction: Routledge.

Sun, M., \& Meng, X. (2009). Taxonomy For Change Causes And Effects In Construction Projects. International Journal of Project Management, $27(6), 560-572$.

Sweis, G., Sweis, R., Abu Hammad, A. \& Shboul, A. (2008). Delays In Construction Projects: The Case Of Jordan. International Journal of Project Management 26, $665-674$.

Walker, A. (2000). Project Management in Construction, Oxford, Blackwell Science Ltd. 